\title{
COMMENTARY
}

\section{An Office of Experiential Education Rotation for APPE Students}

\author{
Riley J. Steenhoek, BS, Lisa M. Richter, PharmD \\ North Dakota State University, College of Health Professions, Fargo, North Dakota
}

Corresponding Author: Lisa M. Richter, North Dakota State University, College of Health Professions, Fargo, ND. Tel: 701-2315178. Email: lisa.richter.1@ndsu.edu

Submitted October 18, 2020; accepted April 21, 2021; ePublished April 2021

The Accreditation Council for Pharmacy Education (ACPE) requires 1440 hours of advanced pharmacy practice experiences (APPE). The majority of all APPE hours should be in direct patient care; however, non-patient care electives can also be used to prepare students to become practice ready and explore areas of interest. Many schools of pharmacy (SOP) across the nation offer elective academic rotations, but an office of experiential education (OEE) academic rotation offers a unique academic elective rotation. The following commentary discusses the experiences of an OEE rotation from a faculty and student point-of-view. A detailed list of activities for an OEE rotation is laid out so it can be easily duplicated by other SOPs. The OEE rotation can be completed online or in-person creating greater flexibility with COVID-19 or other unique circumstances.

Keywords: experiential education, APPE, academia, distance learning, preceptor recruitment

\section{INTRODUCTION}

The Accreditation Council for Pharmacy Education (ACPE) requires at least 1440 hours of advanced pharmacy practice experience (APPE) including a minimum requirement of 160 hours in community pharmacy, ambulatory patient care, hospital/health system pharmacy, and inpatient general medicine patient care. ${ }^{1}$ The majority of all APPE hours should be in direct patient care; however, there are possibilities for non-patient care electives to prepare students to become practice ready and explore areas of interest. ${ }^{1}$ One opportunity a school of pharmacy (SOP) and a student pharmacist can take is to offer and complete a rotation with a pharmacist member of the office of experiential education (OEE) at the university.

The experiential education office is typically in charge of over $30 \%$ of a pharmacy student's curriculum and is a vital part of the college. ${ }^{2}$ One longstanding concern for experiential education directors is recruiting, training and keeping skilled preceptors. ${ }^{3}$ With the COVID-19 pandemic stress has been put on experiential education offices with an increased workload for faculty and a decrease in physical rotation sites for students creating a need to offer additional remote rotations. ${ }^{4}$ Placing a student with an experiential education faculty member is a win-win situation for the college and the student. A rotation in experiential education can prepare students to become future mentors, faculty members and preceptors while making valuable contributions in the process.

Previous literature has been published on completing academic APPE rotations, but nothing specifically with an OEE academic rotation. ${ }^{5-9}$ One commentary discussed overcoming potential barriers to implementing an academic rotation. The authors gave a perspective on the rotation from a faculty and student point-of-view, but experiential education specific activities were not mentioned. ${ }^{7}$ Another article outlined an administration focused APPE rotation. It was not specifically precepted by an experiential education director, but rather several other college administrators. Upon completion of the rotation, all students agreed the rotation made them a more effective preceptor however, experiential education specific projects were not discussed. ${ }^{9}$

\section{Office of Experiential Education (OEE) Viewpoint}

At North Dakota State University SOP, the OEE is composed of three faculty and two staff members with a total of 2.05 faculty full time equivalents (FTE) and 2.0 staff FTE devoted to experiential education for approximately 85 students per class. Students are not precepted by the APPE Director who is the APPE course coordinator, but rather the Director of Experiential Outreach \& Assessment. This allows students to have access to the APPE Director for any concerns with the OEE preceptor or rotation. When an institution has only one Experiential Education Director to precept students, we recommend including in the rotation orientation materials that any grade discrepancies or unresolved issues with the preceptor or rotation can be discussed with the preceptor's immediate supervisor and include pertinent contact information. 
ACPE standards related to experiential education have grown in past years resulting in the need for additional personnel resources. ${ }^{10}$ Limited resources in experiential education create ongoing obstacles related to preceptor recruitment, development and retention. ${ }^{11}$ Having a student work with the OEE for their five-week rotation is one way to think creatively as to how to meet these standards with limited resources. Experiential education commonly encourages preceptors to enable students as pharmacist extenders; however, they infrequently do this to their full potential themselves.

Students are a great asset in creating preceptor development materials, assisting in experiential quality assurance and can provide their point-of-view on important decisions made by the OEE and the SOP. Students can help with preceptor orientation and retention via site quality assurance phone calls and virtual and in-person site visits. Reports are run from the rotation management system by the experiential office with past site visits and student evaluations. Prior to assigning quality assurance phone calls the evaluations are briefly reviewed by the preceptor. Any sites that require follow up for poor performance are handled by the preceptor. Virtual and in-person site visits are conducted along with the preceptor, so the student's main role is in providing preceptor education instead of delivering constructive feedback to the site. With our current rotation structure students have not focused on preceptor recruitment, however this is an area that future students could be involved in with their increased knowledge of social media and technology that is generally superior to OEE faculty members. Other schools may choose to assign different student responsibilities based on the current priorities of the OEE. The rotation gives a great opportunity to teach students about experiential education and get them interested in academia and precepting. Academic topics and activities are included in every rotation in addition to experiential specific activities. The rotation can be customized to fit the student's interests and allows an opportunity for experiential faculty to get to know students in a more personal setting than in the classroom. The rotation also offers the opportunity for experiential faculty to stay involved in the actual precepting process. The rotation has proven to be beneficial for our experiential office, preceptors and for students.

Precepting a student on an academic OEE rotation is not without some preparation on the part of the faculty member to ensure a successful rotation. Students submit their rotation objectives prior to the start of the rotation to allow for customization of the rotation. All non-patient care elective rotations also require a drug information request, an article discussion/journal club, a student led preceptor update, an evaluation of the site/preceptor and additional projects as assigned. Most students were not scheduled for this specific rotation prior to the pandemic and switched into the rotation last minute when a different rotation site unexpectedly canceled. This format could also be used if the student had a need for extended quarantine at a site unable to accommodate remote learning. To help with this a running list of project ideas is maintained by the preceptor and matched with student interest. A calendar is provided to students with all major assignments, meetings, daily touch-bases and evaluations scheduled so students know what to expect and can manage their time accordingly. Larger projects, for example writing a commentary, is broken down into smaller weekly assignments (week 1 literature search due, week 2 outline due, week 3 first draft due, week 4 second draft due, week 5 final draft, tables and references due). It is noted on the calendar that the schedule is subject to change as necessary. One or two students may complete the rotation at a time depending on need and interest. One student allows for a more customizable experience and more individual feedback; however, two students allow for greater collaboration and idea sharing and only requires slightly more work on behalf of the faculty member. Regardless of the number of students per rotation a well-planned experience with a motivated student can easily result in a net gain in productivity for the rotation period for the experiential education faculty member.

Students are evaluated with the standard SOP non-patient care elective entrustable professional activity (EPA) evaluation both verbally and electronically at both the midpoint and final evaluation. The preceptor solicits verbal feedback about the rotation experience during both evaluations. Additionally, the preceptor is evaluated anonymously by the student using the standard evaluation form upon completion of the rotation.

\section{Student Viewpoint}

When students attend pharmacy school and complete APPE rotations they expect a positive experience throughout. Students are not aware of the work that needs to be done by faculty to create a successful learning experience. On my OEE APPE rotation I received a firsthand look at didactic and experiential academia. Since the rotation took place during the COVID-19 pandemic I had a unique experience of witnessing additional challenges faculty have faced. In the didactic coursework faculty had to effectively develop curriculum to meet the needs of distance learning. In experiential education, the office had to adjust to an increased workload with many rotation sites not accepting students. Pharmacy faculty had to overcome many obstacles, but I was able to contribute to solutions and saw how rewarding teaching can be through students' success and appreciation.

The rotation proved to be a valuable learning experience in academia and experiential education. My preceptor for the rotation was the Director of Experiential Outreach and Assessment but she also had responsibilities in the classroom. 
In the subject of teaching, I was able to learn about instructional design, importance of assessment, experiential education and the science of teaching and learning through topic discussions. I had great experiences in assessment by writing test questions for the classes my preceptor was responsible for and in a larger setting through participation in the SOP assessment committee pre-ACPE virtual accreditation visit meeting. With a deeper understanding of pedagogy, it has been easier for me, in turn, to learn new material. I developed a new interest and appreciation of scholarship through my work in writing a manuscript and a commitment to service by presenting at a pharmacy student organization meeting. The experiential education opportunities the rotation provided such as creating multiple preceptor development materials and participating in site quality assurance has given me the tools to become a successful preceptor.

As a residency track student my preceptor tailored the rotation for my interests. I was encouraged to attend seminars and residency showcases to aid in my preparation. I was required to submit my Curriculum Vitae (CV) to the NDSU Career Center as well as to my preceptor. We reviewed areas of weakness in my CV (such as lack of scholarship experience) and purposefully included those on the rotation. As a former PGY1 Residency Program Director my preceptor gave me great tools to prepare me for residency interviews and life as a resident. This preparation combined with a focus on preceptor development and site quality assurance during the rotation further solidifies my desire to precept learners in my clinical practice in the future.

\section{Flexible Learning}

An academic rotation with the office of experiential education is considered a non-patient care elective at our SOP. A non-patient care elective provides great flexibility for student learning, especially during times of a pandemic. Eiland and colleagues' concluded students will benefit from an academic rotation without regard to physical location. ${ }^{9}$ To limit exposure with COVID-19, students on rotation during the pandemic were completely remote or remote plus one day a week in-person with the preceptor. The daily touch-base meetings that were conducted for the APPE students on this rotation were to give direction on projects, feedback and discuss the upcoming calendar of events. Remote daily communication occurred via Zoom, Blackboard Collaborate, telephone, email and/or text messages.

With the majority of teaching at our institution delivered with the HyFlex model (ability to attend in-person or remotely via videoconference) this allowed the same flexibility to an APPE experiential rotation student. This can be particularly helpful if a student has a rotation unable to accept them with short notice so the student can remain living where they have housing or if a situation presents where a student is expected to need extended quarantine. In-person or remote students can teach a lecture, participate in rotation site visits, speak at pharmacy organization meetings, contribute to scholarly activities, and receive feedback on projects. A complete list of activities that experiential education APPE students have participated in is included in Table 1. Experiential education provides many additional opportunities for APPE students above an academic rotation alone.

\section{Future Preceptor Recruitment}

When APPE students are knowledgeable in experiential education and academia before becoming licensed pharmacists the entire pharmacy community benefits. Well trained pharmacists in a teaching or precepting role will continue to benefit the next generation of pharmacists to enhance health care, patient-centered care, and interprofessional education. Students on an OEE APPE can read and discuss ACPE standards related to experiential education, develop preceptor training materials, participate in on-site or remote preceptor orientation, training and site evaluation, and contribute to other experiential education projects. Taking a deep dive into precepting topics provides a foundation for students to become leaders in precepting for future pharmacy students.

\section{Privacy Concerns/FERPA}

Remote learning for a student in an OEE role can raise challenges with privacy and confidentiality. Students are routinely trusted with confidential patient information on clinical rotations and expected to adhere to HIPAA requirements. It is reasonable to expect the same professional conduct in an academic setting. Students must read the University Family Education Rights and Privacy Act (FERPA) information sheet and sign that they have read and understand the information. Students are also instructed if they are included in discussions about any rotation changes necessary due to COVID-19 they are to let the OEE team communicate these changes rather than the student notifying classmates. When the student is assigned to write exam questions there is a discussion with the student about the need to keep questions secure and uphold the honor code. Generally, the student exam questions are modified slightly prior to use due to writer inexperience and to help ensure exam integrity. In the future it would be advised to discuss with the student saving all work to the school's file hosting service and not to the student's personal computer. 


\section{CONCLUSION}

An academic APPE rotation can prepare students for a career in academia, but an academic rotation with the OEE can take it even farther by teaching students' valuable skills in preceptor training and quality assurance. The experiential education faculty and student both benefit from the completion of the rotation, and the flexibility of the rotation is ideal for situations where in-person rotations are not possible without sacrificing a learning experience for students. An OEE APPE rotation exposes students to a unique experience that will continually improve the next generation of pharmacists in practice and precepting.

\section{REFERENCES}

1. Accreditation Council for Pharmacy Education (ACPE). Accreditation Standards and Key Elements for the Professional Program in Pharmacy Leading to the Doctor of Pharmacy Degree. https://www.acpeaccredit.org/pdf/Standards2016FINAL.pdf. Accessed September 29, 2020.

2. Gibson MJ, Bradley-Baker LR, Bush CG, Nelson SP. Reassessment of health-system capacity for experiential education requirements. Am J Pharm Educ. 2017;81(9):6014. doi:10.5688/ajpe6014

3. Brackett PD, Byrd DC, Duke LJ, et al. Barriers to expanding advanced pharmacy practice experience site availability in an experiential education consortium. Am J Pharm Educ. 2009;73(5):82. doi:10.5688/aj730582

4. Fuller KA, Heldenbrand SD, Smith MD, Malcom DR. A paradigm shift in US experiential pharmacy education accelerated by the COVID-19 pandemic. Am J Pharm Educ. 2020;84(6):ajpe8149. doi:10.5688/ajpe8149

5. Sylvia LM. An advanced pharmacy practice experience in academia. Am J Pharm Educ. 2006;70(5):97. doi:10.5688/aj700597

6. Haines SL, Summa MA, Peeters MJ, et al. Toolkit for US colleges/schools of pharmacy to prepare learners for careers in academia. Curr Pharm Teach Learn. 2017;9(5):750-762. doi:10.1016/j.cptl.2017.05.002

7. Harrington EA, Gawronski KM. An advanced pharmacy practice experience in academia: More benefit than burden! Curr Pharm Teach Learn. 2018;10(4):399-402. doi:10.1016/j.cptl.2017.12.022

8. Eiland LS, Staton AG, Stevenson TL. Providing an academic APPE elective via videoconference between offcampus faculty and students. Am J Pharm Educ. 2018;82(8):6645. doi:10.5688/ajpe6645

9. Medina MS, Autry MT, Draugalis JR, Neely SB, Shreffler MR, Hausner SB. Longitudinal outcomes of an elective academic and administrative advanced pharmacy practice experience. Am J Pharm Educ. 2019;83(3):6587. doi:10.5688/ajpe6587

10. Danielson J, Craddick K, Eccles D, Kwasnik A, O'Sullivan TA. A qualitative analysis of common concerns about challenges facing pharmacy experiential education programs. Am J Pharm Educ. 2015;79(1):06. doi:10.5688/ajpe79106

11. O'Sullivan TA, Cox CD, Darbishire P, et al. The status and adequacy of preceptor orientation and development programs in US pharmacy schools. Am J Pharm Educ. 2020;84(2):7540. 
Table 1. Rotation Activities Completed by Six APPE students

Activity

Attend Faculty Meetings

Topic Discussions

Journal Clubs

Drug Information Question

Meeting with ACPE accreditation team

Newsletter Article

Complete and Edit CV

Attend Preceptor/Site Visits

Develop Preceptor Development Modules and Teaching Sheets

Generate Exam Questions/Assist in Grading

Prepare a Lecture

Update Site Descriptions

Attend Online Webinars/Meetings

Develop COVID-19 education for experiential education

Manuscript Preparation

EE Pilot for COVID-19 contract tracing

Administer surveys to students related to classroom learning experience during COVID-19

\section{Brief Description}

Faculty meetings transitioned to virtual with COVID-19. Meetings included department meetings, assessment committee meetings, experiential office meetings, faculty learning communities etc.

Topics covered included academia 101, promotion and tenure, ACPE standards, pedagogy, assessment, instructional design, preceptor and faculty development and a student topic of choice.

Each student presented one journal article on the science of teaching and learning and one specific to a topic in experiential education.

Preceptor proposed a question on a drug topic relevant to future teaching. Example: "How does drug treatment change in a septic patient who has COVID-19?"

One student helped the school of pharmacy with the ACPE accreditation visit and represented the $\mathrm{P} 4$ class in an interview with an accreditation member.

Students created seven brief articles on topics of importance to preceptors to include in experiential education biannual newsletters and provided edits for other newsletter articles.

Sent CVs to University Career Center, made edits and sent for final review by preceptor.

Students were independently involved in 35 standardized site quality assurance calls after competency was assured by the EE preceptor. All collected information was reviewed by the EE preceptor. Students attended remote and in-person site visits with the preceptor as allowed. Students were able to contribute to pre-defined sections of the preceptor development on site visits.

Students created a 15 min voice over PowerPoint "Preceptor Bootcamp Module" as well as contributed to a menu of 11 Student Led Preceptor Development Topics for APPE students on rotation.

Students wrote approximately 30 new test questions as many former questions were considered compromised after COVID-19 exam changes in the spring of 2020. They also assisted in grading in multiple courses taught by the preceptor.

Students prepared a lecture and active learning activities that can be delivered via HyFlex.

Updated information on 25 frequently used rotation sites for future students to review prior to choosing rotations

Attended national, state and local pharmacy webinars/meetings of interest. Due to COVID-19 attending meetings virtually was very convenient with no travel

One student reviewed and compiled learning modules, instructions and recommended documentation for COVID-19 education for students who were about to begin their rotations.

Students were involved in literature searches, completing an outline, and writing multiple drafts of a commentary, introduction or discussion sections of a manuscript.

One student helped pilot a program involving COVID-19 tracing with the ND Department of Health as this was being investigated for opportunities for remote hours for experiential education.

Students developed surveys to send to students who had to change to online learning due to the COVID-19 pandemic and reported results to the SOP faculty.

Update SOP EE website

Student created graphic to replace and update text heavy website

NDSU=North Dakota State University; COVID-19=Coronavirus 2019; CV=curriculum vitae; ND=North Dakota; EE=experiential education; SOP=School of Pharmacy 